\title{
A Study of Drinking Habits in an Office Employees
}

\author{
Mi Joon Lee* (Corresponding Author) \\ Lecturer, Department of Nursing, Hanyang University Professor \\ 133-791, 222 Wangsimniro, Seongdong-gu, Seoul 133-791, Korea \\ E-mail:mijoon63@naver.com
}

\begin{abstract}
Purpose: This study aims to understand drinking awareness, drinking experiences, problem drinking, the money paid annually for drinks by employees at a single company and provide basic data for the development of moderate drinking program customized for them. Methods: It was carried out with 1,838 male and female employees working at a single company in several regions in December 2012, and excluding 12 persons with a data error, subjects in the final analysis were 1,826 persons. For a statistical analysis, the SPSS 19.0 was used. Results: General characteristics of the subjects included questions asking their sex, age, position and monthly income. 194 persons (10.6\%) experienced drunk driving at least once in their drinking experiences. The ratio of problem drinkers (over 13) through AUDIT-K was 495 persons (27.1\%), and the ratio of those with alcohol abuse and dependence was 76 persons (4.2\%). Conclusion: Through the above results, it was found that as specific solutions to the employees' problematic alcohol abuse, improvement of their awareness of drinking culture and a project of improvement of drinking for them are necessary, and it is urgently necessary to develop an ongoing education program to detect and manage problem drinkers and those with alcohol abuse and dependence at the worksite.
\end{abstract}

Keywords: Alcohol drinking, Drinking habits, Drinking Awareness, AUDIT-K

\section{Introduction}

\subsection{Importance of Research}

Korean society tends to be lenient when it comes to many alcohol-related social problems, because it is widely accepted that drinking is a necessary part of personal relationships ("human networks") and social engagement ("social networks"). Nowadays, however, poor alcohol-related behavior has become more widely recognized as a source of problems in family life, business and society at large, rather than just as a problem with the individual. For most Korean corporate employees, drinking tends to be most often with colleagues from work [1]. Consequently, problems that result from alcohol consumption are considered relatively tolerable. Nowadays, alcohol consumption does not merely cause problems to individuals, but has expanded its reach to families, businesses, and the society.

According to the national nutritional surveys held triennially by the South Korean Ministry of Health and Welfare (2008) [5], the percentage values of alcohol-consuming adults were $45.5 \%$ in $1995,59.2 \%$ in 2005 , and $75.5 \%$ in 2008 . Among the alcohol-consuming adults, the percentage of high-risk alcohol consumption was $20.2 \%$ showing an increasing trend. Furthermore, alcohol consumption among women was increasing dramatically, due to a rise in the number of socially active women at 2005 [5]. On the other hand, there have been

\footnotetext{
${ }^{*}$ Corresponding Author
} 
numerous research findings supporting the known biological, psychological, and social differences between men and women in alcohol consumption [3, 7, 8, 11]. To compare between the genders, while nearly $70 \%$ of people in South Korea were reported to drink regardless of gender, both the proportion of drinkers and the frequencies of alcohol consumption were shown to be higher among men than women at 2010 [10]. This implies that men fancy alcohol more than women in terms of both amount and frequency. Alcohol consumption among workers in South Korea is usually considered as an indicator of competence. As a result, workers see company get-togethers where drinking alcohol is forced upon as an obligatory part of their jobs. This drinking culture affects workers' well-being both directly and indirectly.

According to a survey which targeted 4,231 workers in South Korea, it was reported that $83.5 \%$ had an experience of drinking more than once a week and one out of four respondents had drunk excessively at three out of ten drinking parties in Samsung Economic Research Institute, 2004 [2]. Moreover, the final analysis of a survey completed by 500 men and women over the age of 20 working in agricultural areas showed that 241 respondents $(64.8 \%)$ were selected to be problematic alcohol consumers by scoring eight or higher on AUDIT [9].

An investigation into metropolitan workers stated that percentage of alcoholism was directly proportional to age and work experience, three to five times higher among men than women, greater for the married than the unmarried, and high for those dedicated to the sales field [11]. According to Lee (2008) [4], 48.4\% reported to consume alcohol two to four time per month, $41.1 \%$ of men drink more than 10 cups $38.7 \%$ were heavy drinkers, $34.1 \%$ had experienced alcohol-induced damages to daily routine, and $87.8 \%$ drank more than once a month out of around ten instances at company get-togethers.

This study attempts to understand the status of employees' drinking, develop a moderate drinking program to improve their drinking culture for the characteristics of industrial workers and propose basic data for the prevention of problematic alcohol abuse.

\subsection{Importance of Research}

This study aims to understand the employees' drinking status and provide basic data for the development of a drinking improvement program customized for industrial workers, and its specific purposes are as follows:

1) To identify the general characteristics of the industrial workers;

2) To understand how the employees perceive their drinking experiences;

3) To understand the subjects' monthly average money paid for drinks; and

4) To understand the degree of the subjects' problematic drinking and check whether there is a difference between males and females.

\section{Method}

\subsection{Subjects}

This study was conducted with 1,338 employees aged over 20 at a single company in several regions. A survey to which the subjects' consent was obtained was conducted online, and their responses were collected. Excluding data of 12 persons with an error, those of the total 1,326 were used for the final analysis.

\subsection{Ethical Considerations}

After obtaining the approvals by the human resource departments and judicial in the company, purposes of this study were posted on the company online. This study only 
targeted the employees who self-directed agreed to participate. The terms of agreement stated that the questionnaire data shall be used for research purposes only and confidentiality related to the study shall be guaranteed. Agreeing to this study was prerequisite for questionnaire handing-out [1].

\subsection{Research Tools}

Developed by WHO, Alcohol Use Disorder Identification Test (AUDIT) is a handy assessment tool which looks for traces of dangerous and harmful alcohol consumption. This test was utilized for identifying problematic drinkers in their early stages. At the time of its development, sensitivity of $92 \%$ and specificity of $93 \%$ were observed. Lee (2008)'s AUDIT-K [4] credibility was originally Cronbach's $\alpha=.86$, the revised one used in this study Cronbach's $\alpha=89$. The modified one for this study showed Cronbach's $\alpha=.92$ [1]. A total of 10 questions comprise this assessment tool. A score in the range of $1-12,13-19$, or 20 or more indicates a normal drinker, problematic drinker, and alcohol abuse people respectively. AUDIT-K is a modified version of the original AUDIT to better suit the conditions of South Korea. As research tools, structured questionnaires were used, and the contents of them were general characteristics, consisting of 5 questions about gender, age, business position, business area and monthly income; 10 questions on Alcohol Use Disorder Identification Test-Korea (AUDIT-K) to understand the degree of problem drinking; 5 questions asking knowledge about alcohol; 5 about drinking experiences; and 1 about money paid for drinks. As a tool to measure drinking experiences, three in the company doctors and one professor of nursing and the questionnaires were composed of a Likert 5 point scale.

\subsection{Data Analysis}

The analysis in this study used the SPSS 19.0. The subjects' general characteristics, drinking experiences and money paid monthly for drinks were analyzed in real numbers and percentage. To understand the difference in problem drinking depending on their general characteristics, an independent samples t-test was used.

\section{Result}

\subsection{General Characteristics of the Overall Participants}

The subjects in this study were $45.5 \%$ males ( 830 subjects) and $54.5 \%$ females (996 subjects). The most prevalent age group was the 30's (39.0\%), followed by 40 's $(34.7 \%), 20$ 's $(22.8 \%)$, and over 50 (3.5\%). As for educational achievements, $39.5 \%$ had a college degree or less and $60.5 \%$ were university graduates or higher. The company-wide ranks of the employees were distributed as clerks (43.6\%), assistant managers $(22.2 \%)$, deputy managers $(14.8 \%)$, managers $(14.6 \%)$, general managers $(4.3 \%)$, and executive directors $(0.4 \%)$. The employees' responsibilities were divided into management support (17.2\%), sales/marketing (46.9\%), research and development (also known as R\&D) (2.8\%), customer service (14.5\%), and etc. (18.7\%). Most of the subjects earned a monthly income of less than 3 million won $(41.0 \%)$, followed by 3 to 4 million won $(25.2 \%)$ and more than 4 million won (33.8\%). For working area, most of them $(1,043$ persons) worked in Seoul $(57.1 \%)$, followed by Gyeonggi-Do (7.4\%) and Busan $(6.0 \%)<$ Table 1>. 
Table 1. General Characteristics of Participants

\begin{tabular}{|c|c|c|}
\hline Variables & Type & Number (\%) \\
\hline Gender & $\begin{array}{c}\text { Male } \\
\text { Female }\end{array}$ & $\begin{array}{l}830(45.5) \\
996(54.5)\end{array}$ \\
\hline Age & $\begin{array}{l}\text { 20 29 years } \\
30 \sim 39 \text { years } \\
40 \sim 49 \text { years } \\
\text { Over } 50 \text { year }\end{array}$ & $\begin{array}{c}416(22.8) \\
712(39.0) \\
634(34.7) \\
46(3.5)\end{array}$ \\
\hline Responsibility & $\begin{array}{c}\text { Management Support } \\
\text { Sales/ Marketing } \\
\text { R\&D } \\
\text { Customer Service } \\
\text { etc }\end{array}$ & $\begin{array}{c}314(17.2) \\
856(467.0) \\
51(2.8) \\
264(14.5) \\
341(18.7)\end{array}$ \\
\hline Monthly Income & $\begin{array}{c}\text { Under } \$ 3,000 \\
\text { Over } \$ 4,000\end{array}$ & $\begin{array}{l}758(41.0) \\
617(33.8)\end{array}$ \\
\hline Office Region & $\begin{array}{c}\text { Seoul } \\
\text { Gyeonggi-Do } \\
\text { Incheon City } \\
\text { Daejeon/Chungcheong-Do } \\
\text { Gangwon-Do } \\
\text { Jeju-Do } \\
\text { Daegu/Kyeongsanngbuk -Do } \\
\text { Busan/Kyeongsangnam-Do } \\
\text { Jeonju/ Jeonlabuk -Do } \\
\text { Gwangju/ Jeonlanam -Do }\end{array}$ & $\begin{array}{c}1,042(57.1) \\
135(7.4) \\
97(5.3) \\
104(5.7) \\
30(1.6) \\
12(0.7) \\
99(5.4) \\
176(9.6) \\
36(2.0) \\
95(5.2)\end{array}$ \\
\hline
\end{tabular}

\subsection{Subjects}

Regarding questions about drinking experiences, to the question, "Our department always drinks alcohol in the company get-together," 732 persons $(40.1 \%)$ responded that it does not while 1,094 (59.9\%) responded that it does, so more of them responded that they always drink alcohol in the company get-together. To the question about heavy drinking, "I have an experience that I could not concentrate on work on the day after drinking," 1,473 persons $(80.7 \%)$ responded that they did while $353(19.3 \%)$ responded that they did not. To the question "About an experience of drank fight with a coworker?" 1,798 persons $(98.5 \%)$ responded that they did not while $28(1.53 \%)$ responded that they did. To the question about an experience of absence on the day after drinking due to drinking, 1,786 persons $(97.8 \%)$ responded that they did not while $40(2.2 \%)$ responded that they did. To the question about an experience of drunk driving, 1,632 (89.4\%) responded that they never did while $194(10.6 \%)$ responded that they did at least once $\langle$ Table 2$\rangle$. 
Table 2. Experiences of Alcohol Drinking

\begin{tabular}{|c|c|c|c|c|c|}
\hline \multicolumn{6}{|c|}{$(\mathrm{N}=1,826: \mathrm{No},(\%))$} \\
\hline Categories & Never & $\begin{array}{l}\text { Almost } \\
\text { Not }\end{array}$ & Sometimes & Often & Always \\
\hline $\begin{array}{l}\text { Our department always } \\
\text { drinks alcohol in the } \\
\text { company get-together. }\end{array}$ & $209(11.4)$ & $523(28.6)$ & 385 (21.2) & $400(21.9)$ & $309(16.9)$ \\
\hline $\begin{array}{l}\text { I have experienced a } \\
\text { difficulty in } \\
\text { concentrating on work } \\
\text { on the day after heavy } \\
\text { drinking. }\end{array}$ & $783(42.9)$ & $690(37.8)$ & $273(15.0)$ & $55(3.0)$ & $25(1.4)$ \\
\hline $\begin{array}{l}\text { I have experienced a } \\
\text { drunken quarrel or fight } \\
\text { with a coworker. }\end{array}$ & $\begin{array}{l}1,658 \\
(90.8)\end{array}$ & $140(7.7)$ & $24(1.3)$ & $3(0.2)$ & $1(0.1)$ \\
\hline $\begin{array}{l}\text { I have an experience of } \\
\text { being late or absent on } \\
\text { the day after drinking. }\end{array}$ & $\begin{array}{l}1,623 \\
(88.9)\end{array}$ & $163(8.9)$ & $32(1.8)$ & $3(0.2)$ & $5(0.3)$ \\
\hline $\begin{array}{l}\text { I have an experience of } \\
\text { drunk driving }\end{array}$ & $\begin{array}{l}1,632 \\
(89.4)\end{array}$ & 167 (9.1\%) & $26(1.4)$ & $1(0.1)$ & - \\
\hline
\end{tabular}

\subsection{Monthly Average Money paid for Drinks}

As a result of an analysis of the money paid monthly for drinks by the subjects by occupation, less than 100,000 won accounted for the highest proportion in most occupations. 28 persons (8.9\%) of "Management Support", 78 persons $(9.1 \%)$ of "Sales and Marketing", 4 persons $(7.8 \%)$ of "R\&D", 6 persons(2.3\%) of "Customer Services" and 20 persons $(5.9 \%)$ of "Others" paid more than 500,000 won monthly for drinks. More than 500,000 won accounted for higher proportion in "Management Support", "Sales/Marketing", "R\&D" and "Others" than between 200,000 and 400,000 won. About 190,000 won was spent for drinks monthly on average Table 3. 
Table 3. Monthly Average Money paid for Drinks

\begin{tabular}{|c|c|c|c|c|c|}
\hline & & & & \multicolumn{2}{|c|}{$(\mathrm{N}=1,826: \mathrm{No},(\%))$} \\
\hline Categories & $\begin{array}{c}\text { Management } \\
\text { Support }\end{array}$ & $\begin{array}{c}\text { Sales\& } \\
\text { Marketing }\end{array}$ & R\&D & $\begin{array}{c}\text { Customer } \\
\text { Service }\end{array}$ & etc \\
\hline Under $\$ 100$ & $152(48.4)$ & $420(49.1)$ & $33(64.7)$ & $191(72.3)$ & $216(63.3)$ \\
\hline$\$ 100 \sim \$ 200$ & $78(24.8)$ & $189(22.1)$ & $9(17.6)$ & $36(13.6)$ & $65(19.1)$ \\
\hline$\$ 200 \sim \$ 300$ & $40(12.7)$ & $103(12.0)$ & $3(5.9)$ & $17(6.4)$ & $28(8.2)$ \\
\hline$\$ 300 \sim \$ 400$ & $16(5.1)$ & $66(7.7)$ & $2(3.9)$ & $14(5.3)$ & $12(3.5)$ \\
\hline Over $\$ 500$ & $28(8.9)$ & $78(9.1)$ & $4(7.8)$ & $6(2.3)$ & $20(5.9)$ \\
\hline $\begin{array}{c}\text { Total } \\
\text { (No, \%) }\end{array}$ & $314(100)$ & $856(100)$ & $51(100)$ & $264(100)$ & $341(100)$ \\
\hline
\end{tabular}

\subsection{AUDIT-K (Alcohol Use Disorder Identification-Korea)}

This study used Alcohol Use Disorder Identification-Korea (AUDIT-K), a Korean translated version of the original AUDIT developed by the WHO. Having 10 questions, AUDIT-K scores in the range of $1-12,13-19$, or 20 or higher, and were respectively categorized as normal drinker, problematic drinker, and alcohol abuse people. A total of 1,826 subjects were the targets of analysis Table 4 .

Table 4. AUDIT-K (Alcohol Use Disorder Identification-Korea)

\begin{tabular}{ccc}
\hline Categories & Score & $(\mathrm{N}=1,826:$ No, (\%)) \\
\hline Normal & $0-12$ & $1,255(68.7)$ \\
habitual/Potential & $13-19$ & $495(49.5)$ \\
Alcoholics & $<20$ & $76(4.2)$ \\
\hline
\end{tabular}

\subsection{Comparison of Difference in Alcohol Abuse by Sex}

To check the difference in the subjects' alcohol abuse by sex, an independent samples t-test was conducted. The assumption of normality was satisfied, and the significant probability of alcohol abuse was smaller than 0.05 , so it was confirmed that there was a difference in alcohol abuse between male and female $\left(\mathrm{t}=24.432, \mathrm{p}<0.001^{* *}\right)$. 


\section{Conclusion}

This study attempted to understand the employees' drinking status and use it as basic data for the development of a practical, effective moderate drinking education program for healthy living. The method of study was descriptive research, and a survey was carried out online with structured questionnaires on 1,838 employees working in all areas of a single company, December, 2011. The 1,826 persons were finally analyzed, excluding 12 persons with an error in the collected data, which were statistically processed using SPSS 19.0, and the results were as follows.

First, the participants in this study were 830 males (45.5\%) and 996 females (54.5\%); more female participants than males.

Second, regarding their drinking experiences, 1,632 (89.4\%) did not experience drunk driving while $194(10.6 \%)$ did at least once.

Third, regarding the money paid for drinks monthly, most of them $(1,012)$ spent less than 100,000 won (55.4\%), and the monthly average expenses were about 190,000 won.

Fourth, the subjects' scores in AUDIT-K were 12.7 \pm 4.9 in males and 7.1 \pm 4.9 in females; there is a difference in alcohol abuse by sex.

To sum up the above results, an education for moderate drinking and an effective intervention program are needed to perceive and solve the subjects' problem drinking and alcohol related problems. Since most employees are greatly affected by the atmosphere of the workplace at which they work, positive changes should be induced company-wide. It is important to introduce strategic development through an active education program for early detection and management of problematic alcohol abusers and those with alcohol dependence in the company, so that the employees' awareness about drinking culture is changed.

Through this survey, the following suggestions are made.

First, a customized in the company moderate drinking program should be developed and applied;

Second, various in the company programs should be studied to induce the participation in an education program for moderate drinking and their effectiveness should be verified; and

Third, organizational culture should be reviewed and measures to provide learning of selfdirected changes should be prepared to change the employees' drinking culture in the company.

\section{References}

[1] A. S. Oh, Editor: Science and Engineering Research Support Society, Proceeding of the 2014 International Workshop on Bioscience and Medical Research, (2014), August 20-24; Jeju, Korea.

[2] D. W. Um, "Study on the work's drinking style and company's solution", Samsung Economic Research Institute, vol. 469, (2004), pp. 1-23.

[3] G. L. Fisher and T. C. Harrison, "Substance Abuse", Information for School Counselors, Social Workers, (2008), Therapists, and Counselors (4th Edition).

[4] H. K. Lee, "A Survey on Alcohol use of Workers", J. Korean Psychiatric Mental Health Nursing, vol. 17, no. 2) (2008), pp. 182-190.

[5] Ministry of Health and Welfare for Public health data, http://www.mw.go.kr

[6] Ministry of Health and Welfare for Korean National Nutrition Survey, (2008).

[7] M. Holmila and K. Raitasalo, "Gender Differences in Drinking, Why do They Still Exist?. Addiction", vol. 100, no. 12, (2005), pp. 1763-1769.

[8] S. K. Walitzer, A. Dearing, (2006), "Gender Differences in Alcohol and Substance Use Relapse", Clinical Psychology Review, vol. 26, no. 2, (2006), pp. 128-148.

[9] S. H. Yang, J. H. Kim, "Drinking Habits of Employees in Farming and Fishing Communities", J. Digital Policy \& Management, vol. 10, no. 10, (2012), pp. 363-372.

[10] Statistics Korea, “A Study on the Status of drinking Survey”, (2010). 
International Journal of Bio-Science and Bio-Technology

Vol.6, No.5 (2014)

[11] T. W. Kim, "Study on Problem Drinking of Office Workers in Seoul”, J. Korean Family Social Work, vol. 1, no. 7, (2001), pp. 35-57.

[12] WHO, "Global Strategy to Reduce the Harmful Use of Alcohol", (2010).

[13] World Health Organization for Health in Information Data, http://www.who.int

\section{Author}

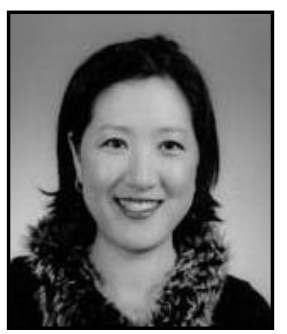

Mi-Joon Lee, She was born in Korea, on October 3, 1963. She is now the Ph.D. student in Nursing of Hanyang University. She is a Lecturer in Department of Nursing, Hanyang University. Her recent interests focus on health care service and bioinformatics. 